ارزيابى تنوع زنتيكى برخى تودههاى بومى كاودانه ايرانى با استفاده از نشانكَرهاى ريزماهواره

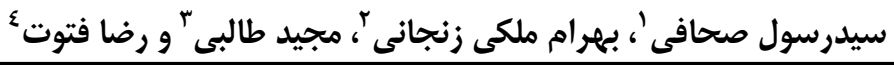

ا- استاديار، دانشگاه ولى عصر (عج) رفسنجان (نويسنده مسوول: s.r.sahhafi@vru.ac.ir)

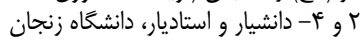

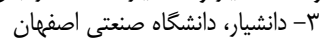

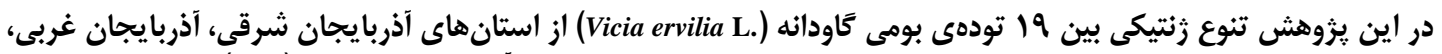

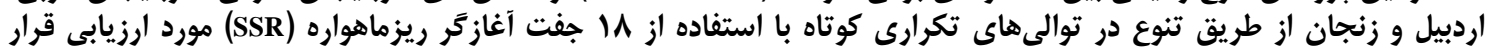

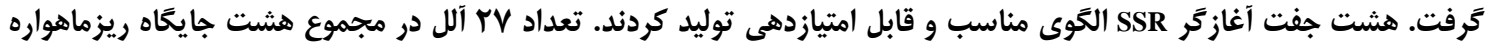

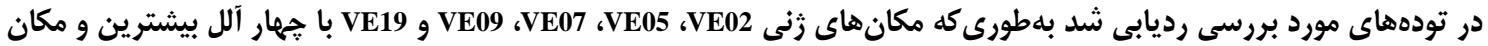

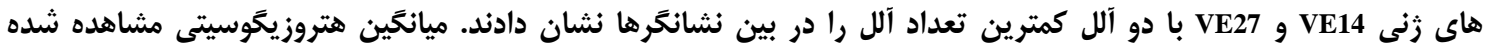

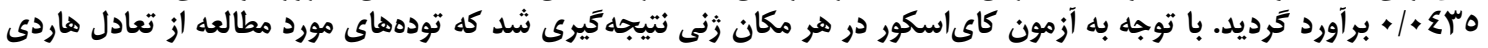

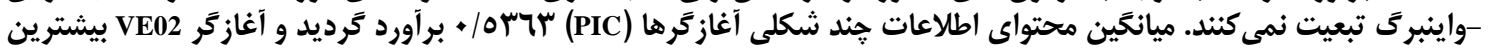

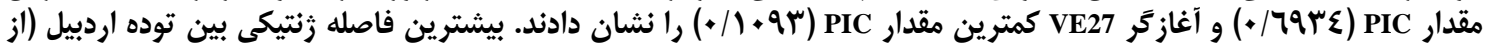

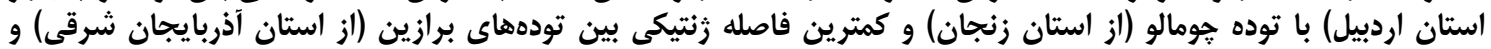

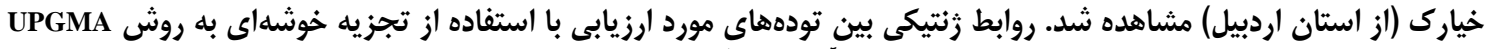

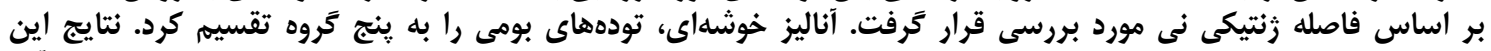

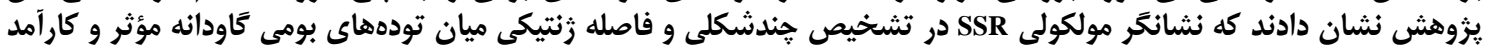

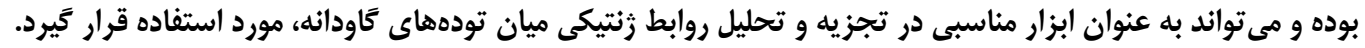

وازههاى كليدى: كاودانه، تنوع زنتيكى، نشانكر هاى مولكولى، SSR

تجزيهيذيرى بالا در جيره نشخواركندكان مورد استفاده قرار

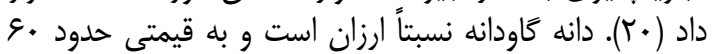

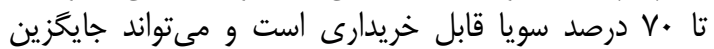

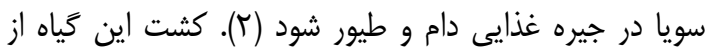

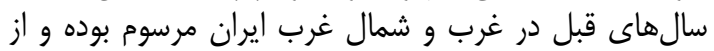

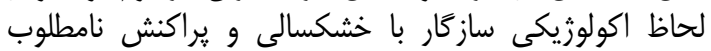

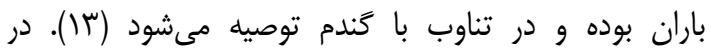

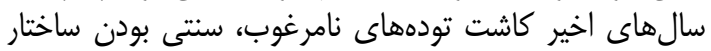

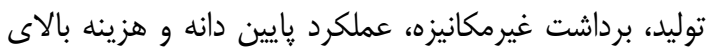

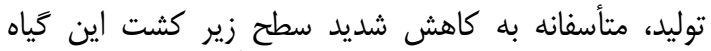

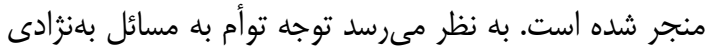

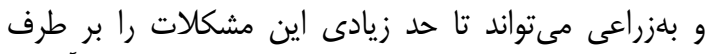

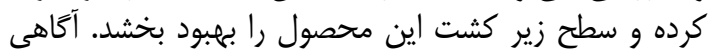

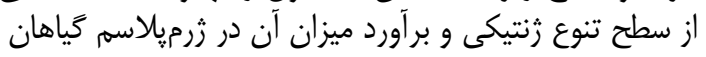

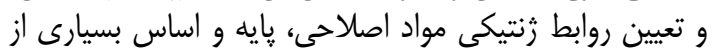

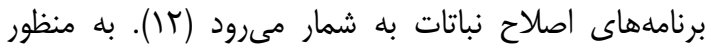

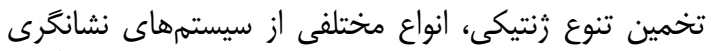

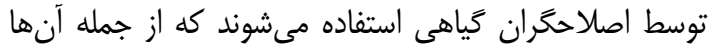

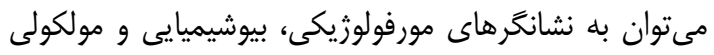

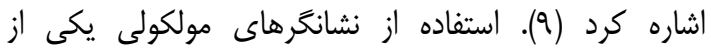

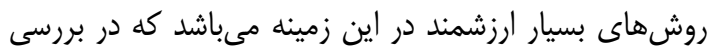

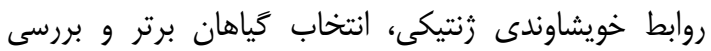

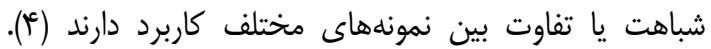

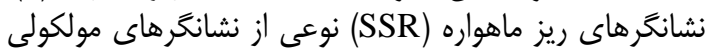

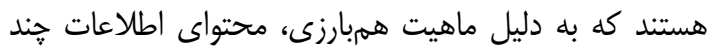

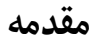
منابع تأمين كننده انرزى و يروتئين حجيمترين و وير

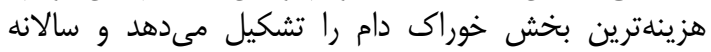

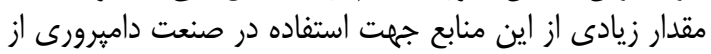

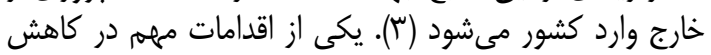

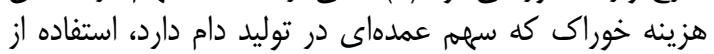

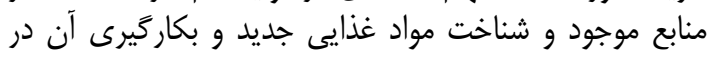

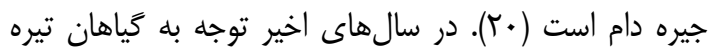

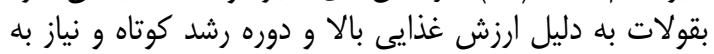

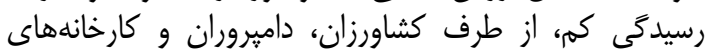

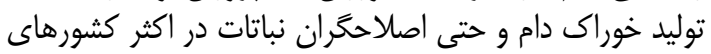

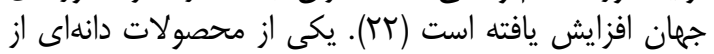

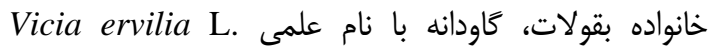

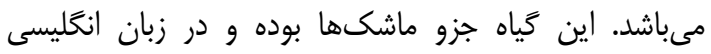

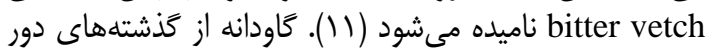

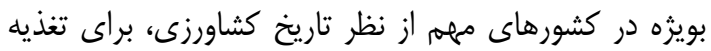

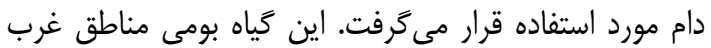

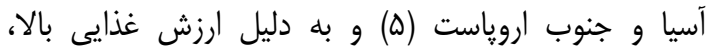

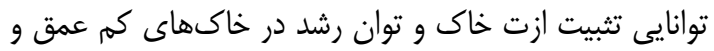

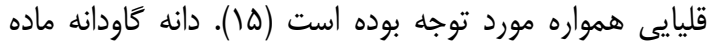

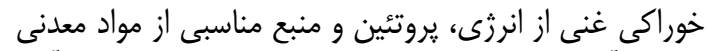

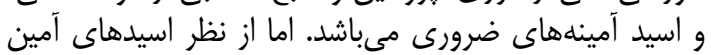

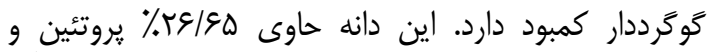

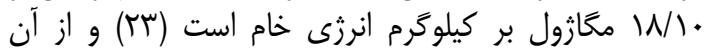
مىتوان بلهنوان يك ماده خوراكى مناسب با قابليت هضم و و 
كلكسيون كاودانهى گروه زراعت و اصلاح نباتات دانشكده

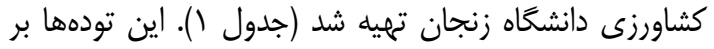

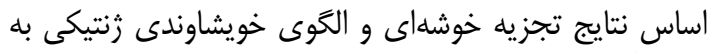

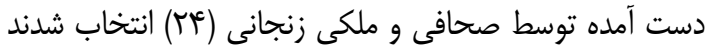

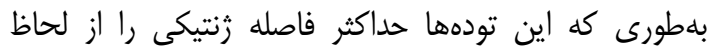

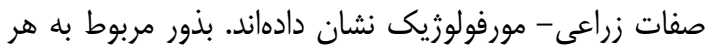

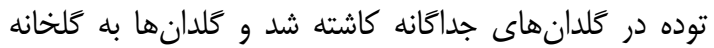

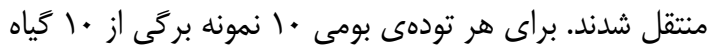

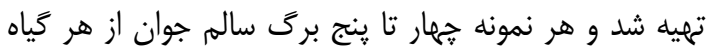

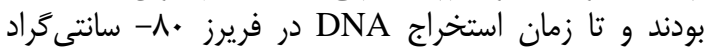

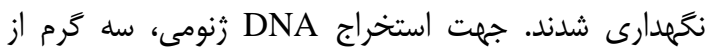

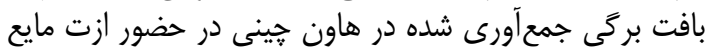
يودر شده و استخراج DNA بر اساس روش

واكنش زنجيرهاى يليمراز و الكتروفورز

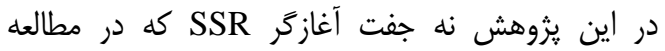

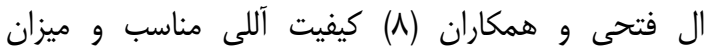

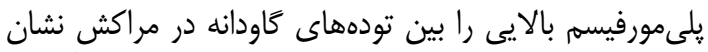

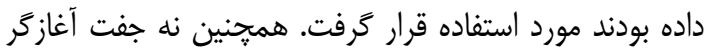

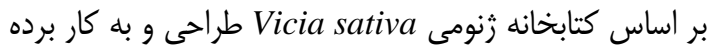

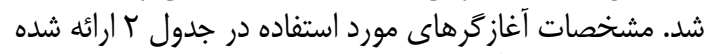

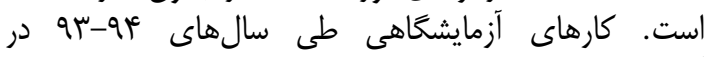

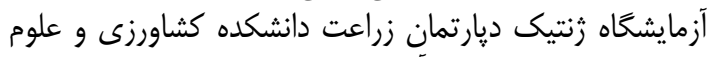

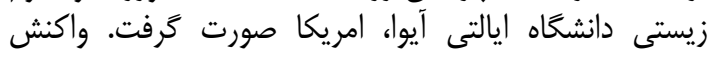

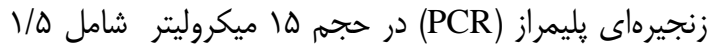

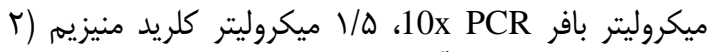

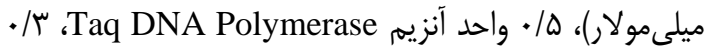

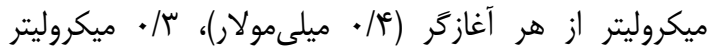

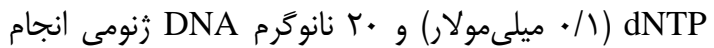

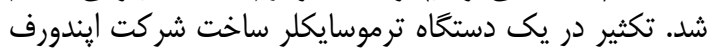

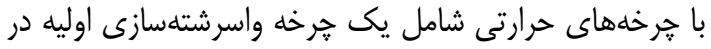

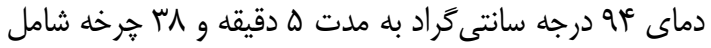

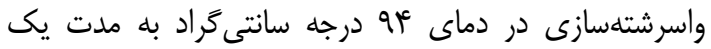

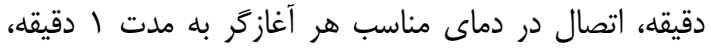

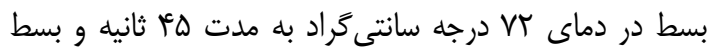

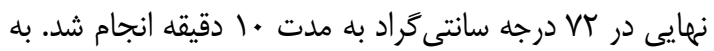

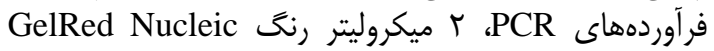
Acid Stains

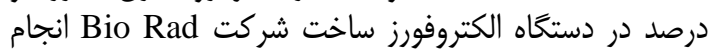

شكلى بالا و توزيع تصادفى در زنوم، ابزارهاى مناسبى براى تئي

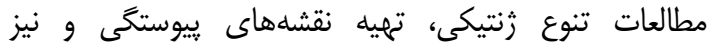

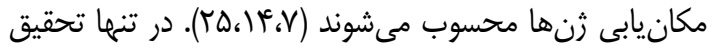

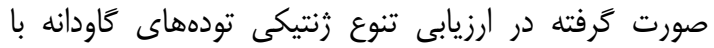

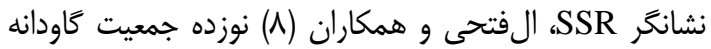

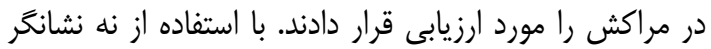

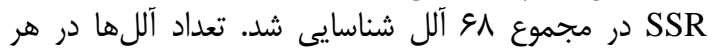

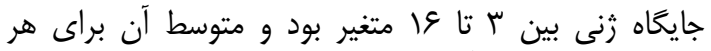

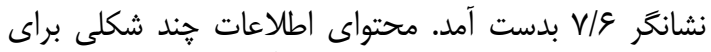

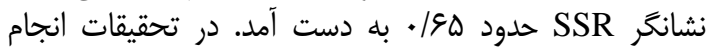

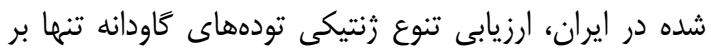

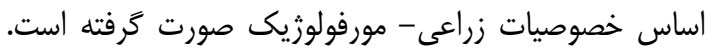

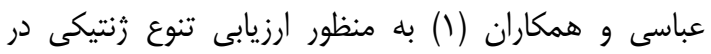

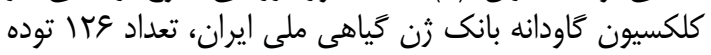

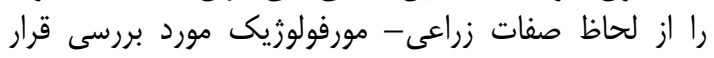

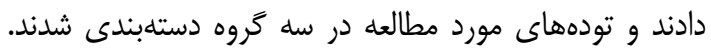

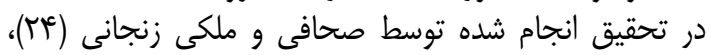

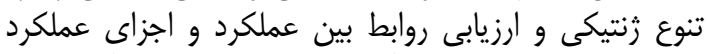

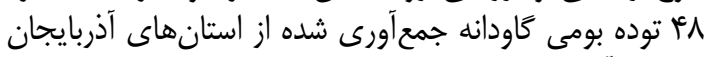

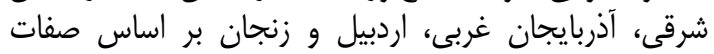

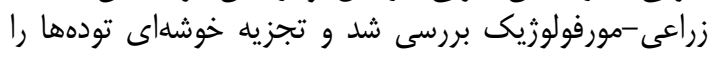

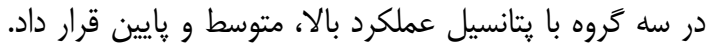

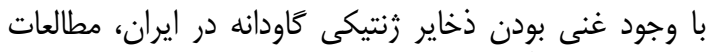

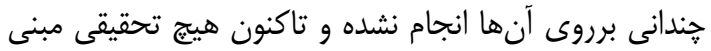

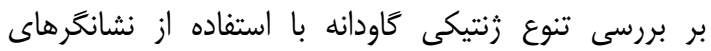

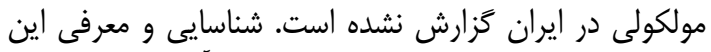

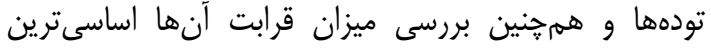

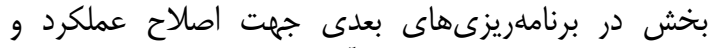

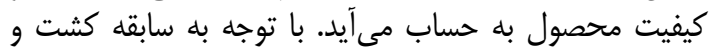

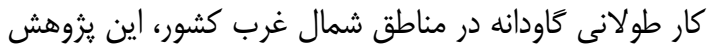

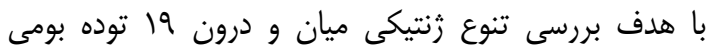

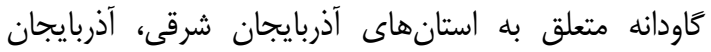

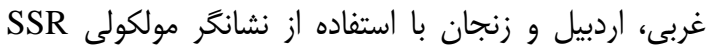

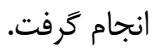

\section{مواد و روشها

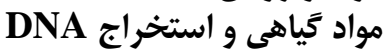

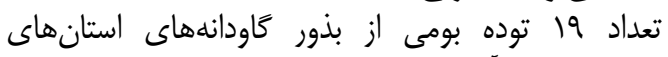
آذربايجان شرقى، آذربايجان غربى، اردبيل و زنجان مودان استود درى 
Table 1. The list of studied bitter vetch landraces جدول 1- تودههاى بومى كاودانه مورد استفاده در آزمايش

\begin{tabular}{|c|c|c|c|}
\hline محل جمع أورى (استان-شهرستان-روستا) & شماره & محل جمع أورى (استان -شهرستان - روستا) & 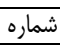 \\
\hline اردبيل- اردبيل-خيارك & 11 & آذربايجان شرقى - اهر - بهل & $T$ \\
\hline اردبيل - خلخال - آل هاشم سفلى & ir & آذربايجان شرقى - ملكان -بايقوت & r \\
\hline اردبيل - سرعين -آلوارس & سו & آذربايجان شرقى - ملكان-يولقنلوى جديد & r \\
\hline اردبيل - نمين - سقزٍى & if & آذربايجان شرقى - ميا & c \\
\hline زنجان - ابهر - داشبلاغ & 10 & آذربايجان شرقى & o \\
\hline زنجان- زنجان - קلكان & 19 & آذربايجان غربى - حالدران -قورول عليا & 8 \\
\hline زنجان- زنجان - جومالو & IV & آذربايجان غربى_ خوى-الند & $\mathrm{v}$ \\
\hline زنجان - زنجان - قلعه & M & آذربايجان غربى- خوى-سكتلو & $\wedge$ \\
\hline زنجان-زنجان- كلوجه & 19 & آذربايجان غربى- خوى-ميدان سفلى & 9 \\
\hline & & اردبيل & 1. \\
\hline
\end{tabular}

جدول r- توالىهاى رفت و برگشت \\ جفت آغازگر ريزماهواره مورد استفاده

Table 2. Backward and forward sequences of the 18 studied SSR markers

\begin{tabular}{|c|c|c|c|}
\hline توالى أغازگرها & نام أغازگر & توالى أغازگرها & 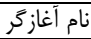 \\
\hline F: GCCTCGTAGATTTGGTTTGATG & VSS256 & F: CAAGCTGGCCACCTAATGC & VE02 \\
\hline R: TGATAATTTGCGGCTTATAGGG & & R: ATATTAAGGGTTTCGAGTTGGG & \\
\hline F: GGTTAAAGGGCGTGATAAGGAT & VSS270 & F: TAGCAAGCCTTTGAACCTTTT & VE03 \\
\hline R: TATTAGCCAACCCAGAAAGAGG & & R: CCTGAAACAGCAAACCAACA & \\
\hline F: GCTTTGTTCATCTGTTGCTTTG & VSS279 & F: TTTAATTTTGCTCCTTGCGG & VE05 \\
\hline R: AGTTCACСTTCССАСАТССТС & & R: CСТTAССАТААССТАААССТААССС & \\
\hline F: CGAAATCTATTGCCACGGTT & VSS288 & F: CTGCTGATGATGTTGTGGATG & VE09 \\
\hline R: ACGTTGTTGTCGGTGTCTTG & & R: GAACACGTGTACGGAGACCA & \\
\hline F: TTTGATTTGTTGGGTGACGA & VSS292 & F: TTTGGAGGCTTTGAGCCTTA & VE14 \\
\hline R: GGAGGAAGAGGTTTGGAAGG & & R: CCCAACAGGGATACCACTTC & \\
\hline F: CAGTTTCCATTGTCAGAAGCAC & VSS298 & F: GTCAGAATCCCCATGTACACAA & VE19 \\
\hline R: TTTCTGTTGTTCATTCGCCA & & R: TGAGTTTTGAGATTTAGCCCTTG & \\
\hline
\end{tabular}

\section{نتايج و بحث}

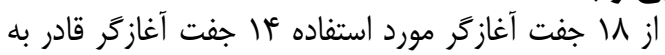

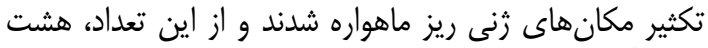

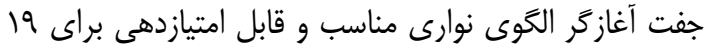

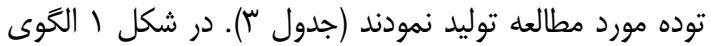

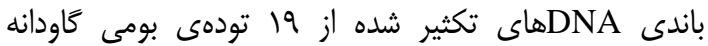

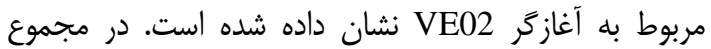

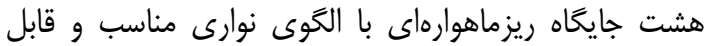

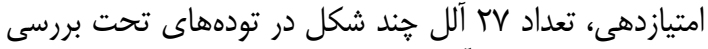

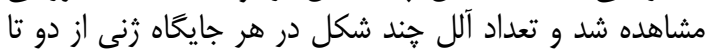

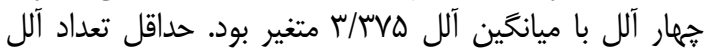

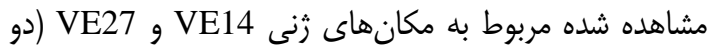

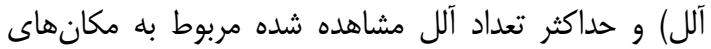

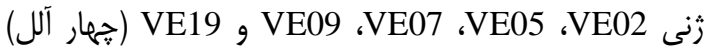

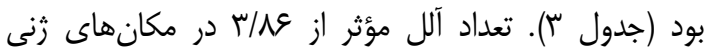

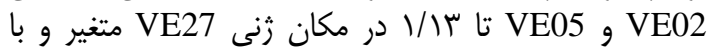

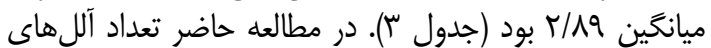
جند شكل مشاهده شده براى مكان ماندان

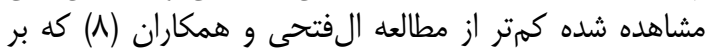

تجزيه و تحليل دادهها

قطعات تكثير شده توسط جفت آغازگرَها امتيازبندى شدها

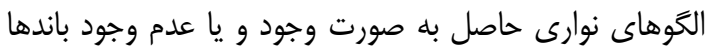

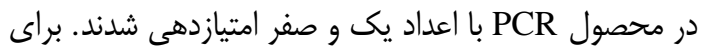

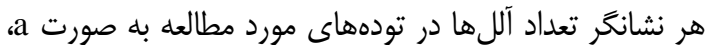

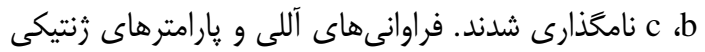

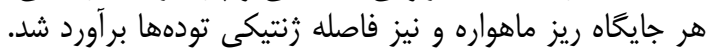

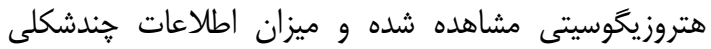

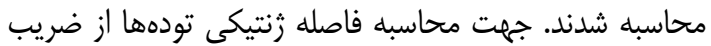

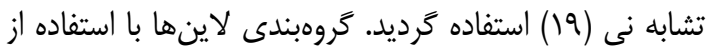

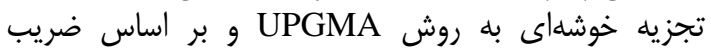

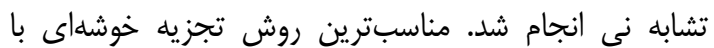

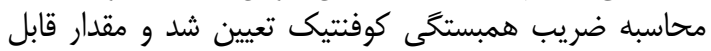

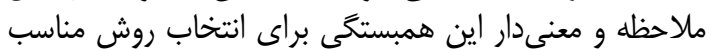

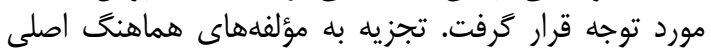
دون Principle Coordinate Analysis دقيقتر روابط زنتيكى بين تودهها و تأييد گروهبندى تجزيه

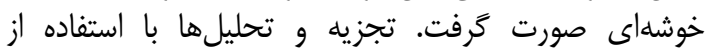

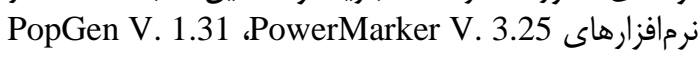
و GeneALex V. 6.5 صورت كرفت. 


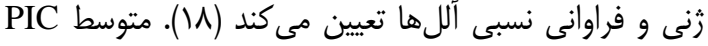

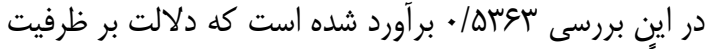

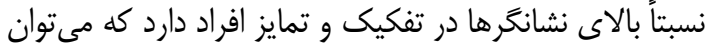

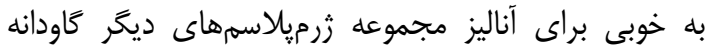

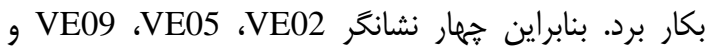

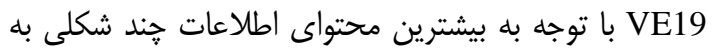

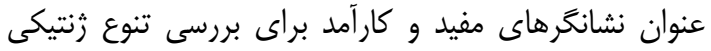

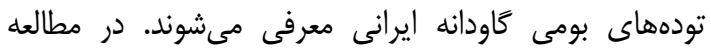

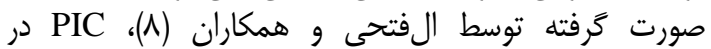

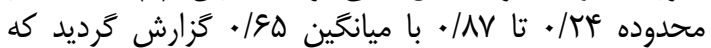

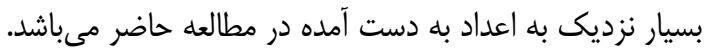

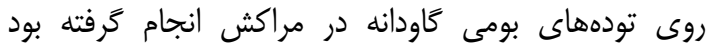

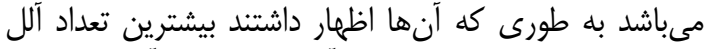

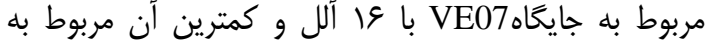

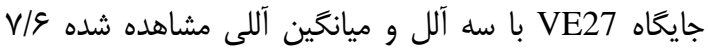

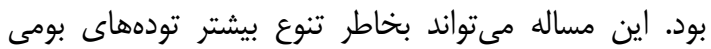

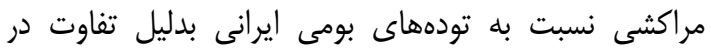

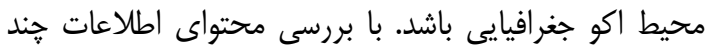

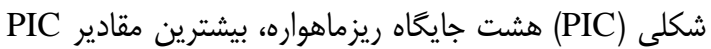

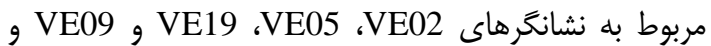

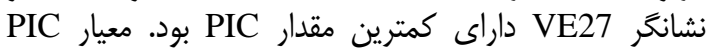
توان تمايز هر آغازكر را از طريق تعداد آللها در يكى مكان

جدول س- دماى اتصال و شاخصهاى تنوع زنتيكى در 19 توده بومى كاودانه براى هشت نشانگر SSR با الخوى مناسب و قابل امتيازدهى Table 3. The annealing temperature and genetic diversity indices of 8 SSR markers in 19 bitter vetch landraces

\begin{tabular}{|c|c|c|c|c|c|c|}
\hline هتروزيغوسيتى شده & محتواى اطلاعات & تعداد آلل & مشاهده شده & دآله اندازه & اتصال & نام آغازگر \\
\hline .1 .194 & . |Qसq| & $r / \varepsilon$. & r & سוT-r|r & $\Delta) / \Delta \stackrel{0}{C}$ & VE03 \\
\hline.$/ \ldots$ & • & T/TV & f & Q & $\Delta \cdot / V \underline{o}_{C}$ & VE07 \\
\hline . I.trA & .19890 & $\mathrm{r} / \Delta \Lambda$ & $f$ & $\Delta r-119$ & $\Delta F^{*} \underline{o}_{C}$ & VE09 \\
\hline . /. TVE &.$/ 1.94$ & سו/1 & $r$ & M & ${ }^{\mu} \underline{o}_{C}$ & VE27 \\
\hline DT & سوسه/. & r/Aq & r/rVQ & - & - & ميانخين \\
\hline
\end{tabular}

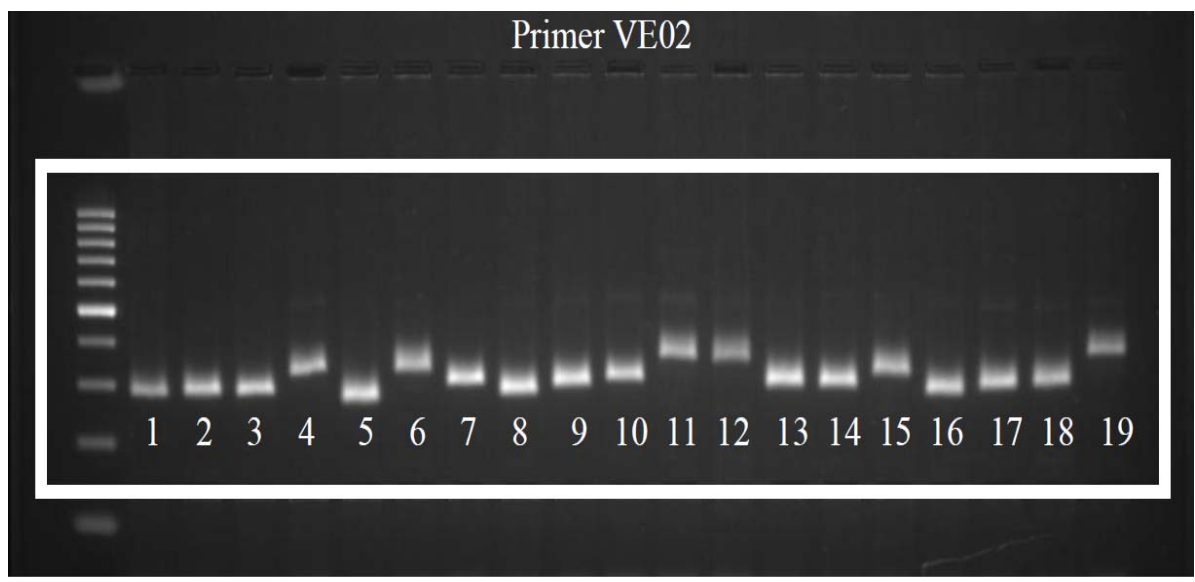

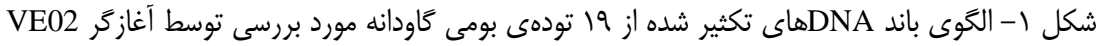
Figure 1. The banding pattern of primer VE02 in 19 bitter vetch landraces

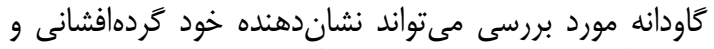

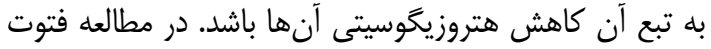

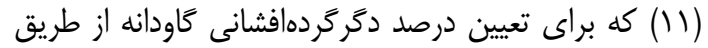

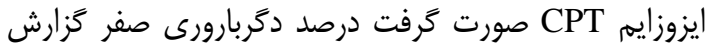

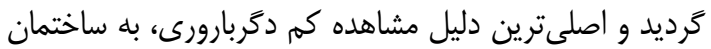

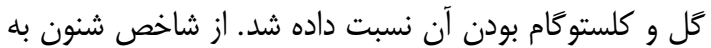

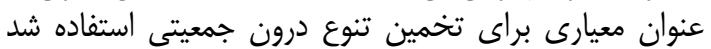

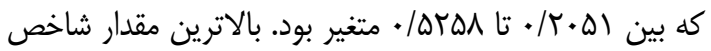

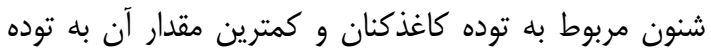

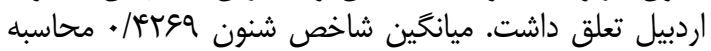

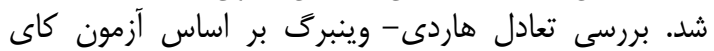

هتروزيخوتى مشاهده شده در تودههاى مورد مطالعه بين

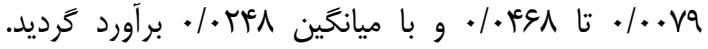

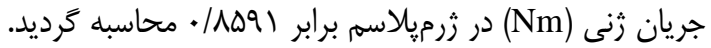

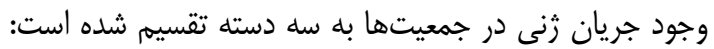

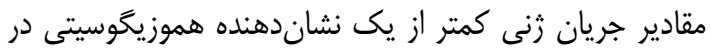

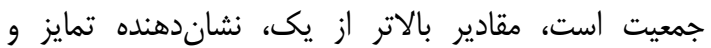

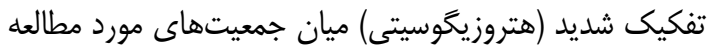

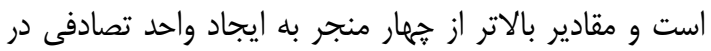

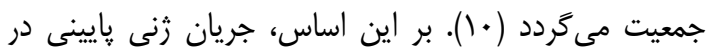

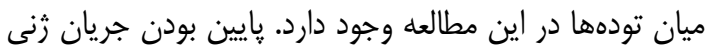

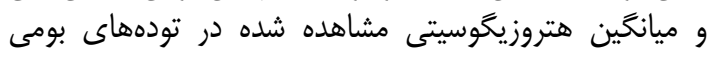


مانند كروههاى يك، جهار و ينج، با توجه به خصوصيات

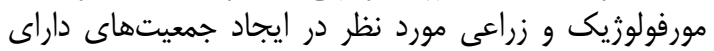

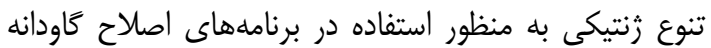

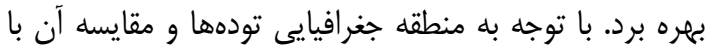

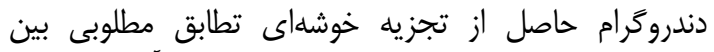

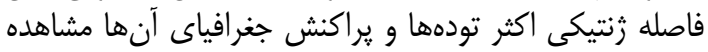

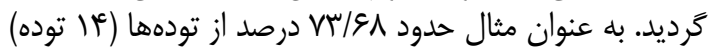

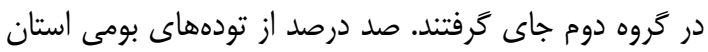

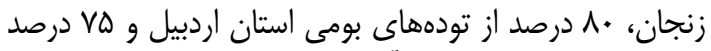

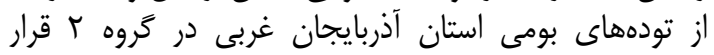

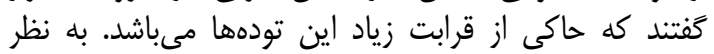

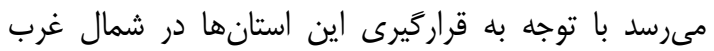

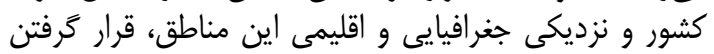

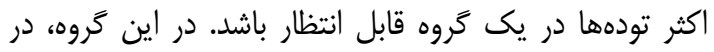

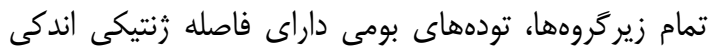

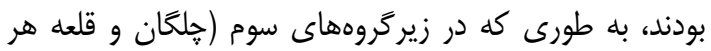

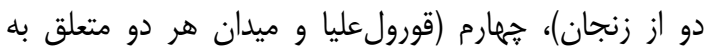

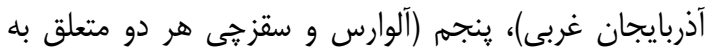

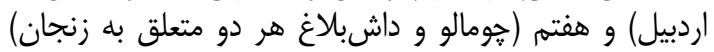

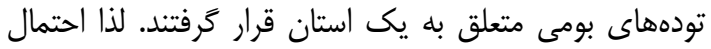

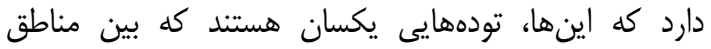

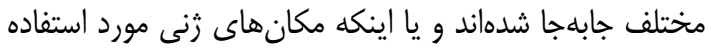

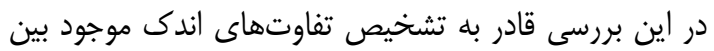

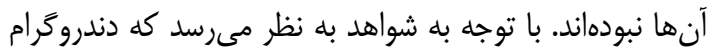

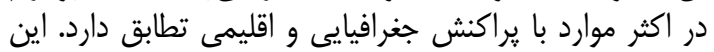

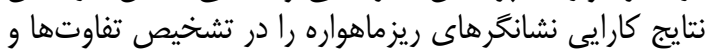

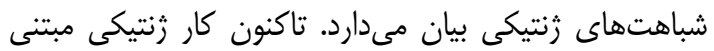

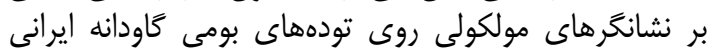

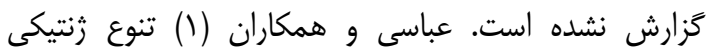

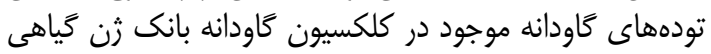

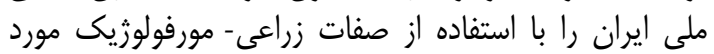

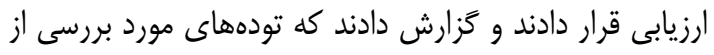

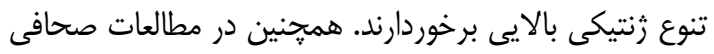

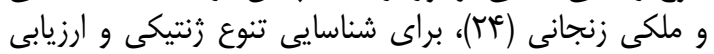

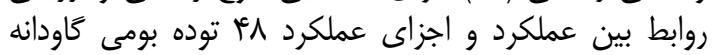

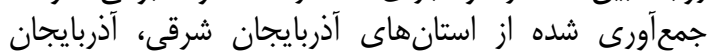

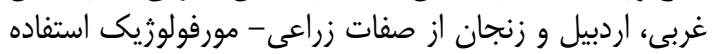

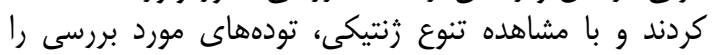
طبقابندى كردند.

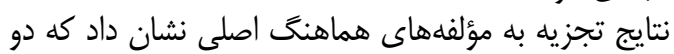

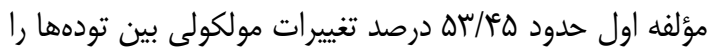

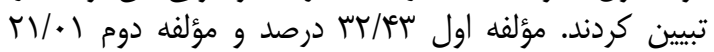

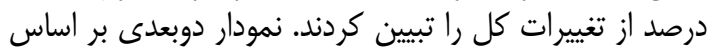

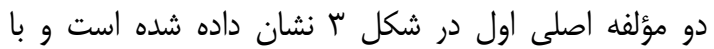

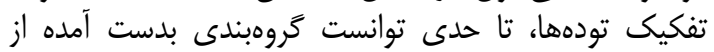

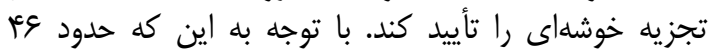

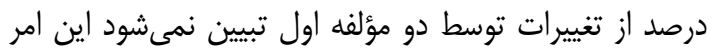

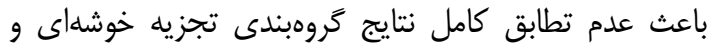

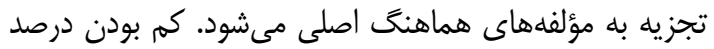

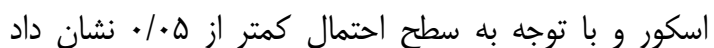

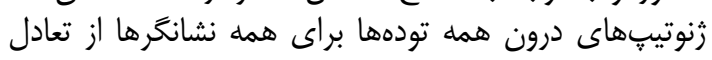

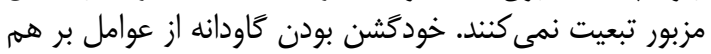

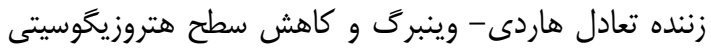

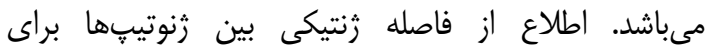

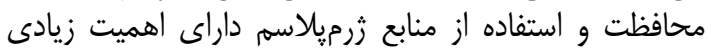

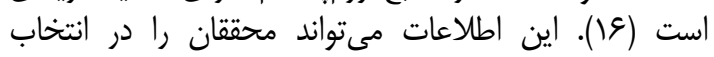
تركيبات والدينى مناسب براى برات بهرهبردارى حدان حداكثر از مواد انداد

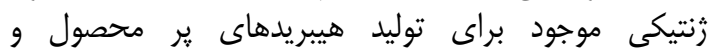

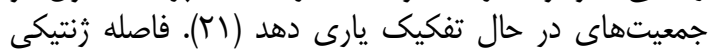

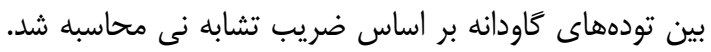

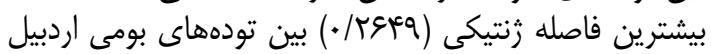

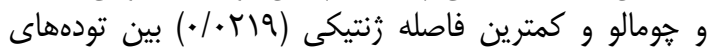

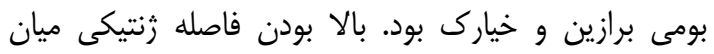

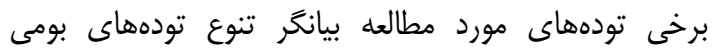

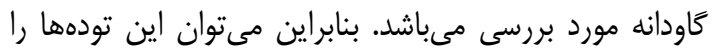

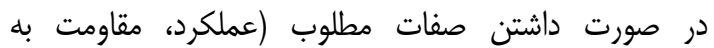

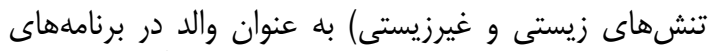

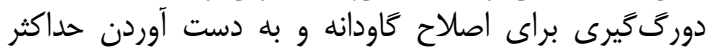

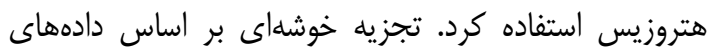

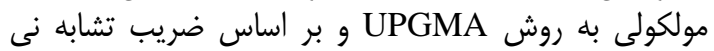

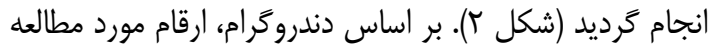

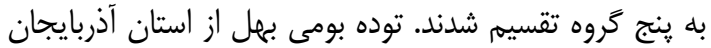

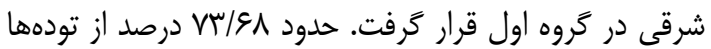

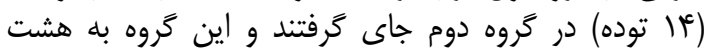

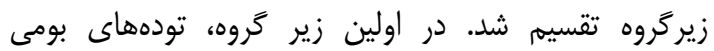

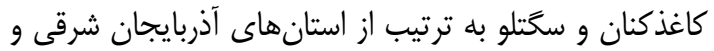

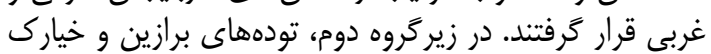

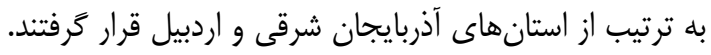

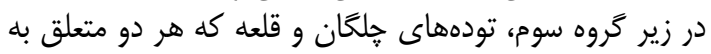

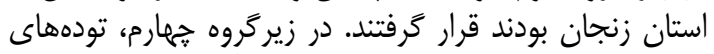

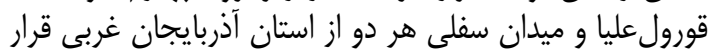

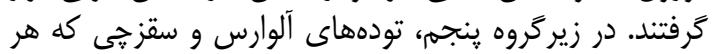

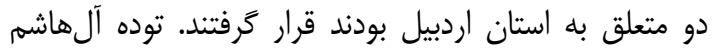

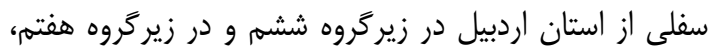

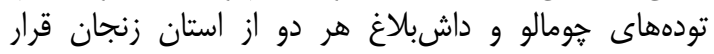

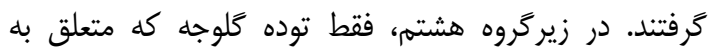

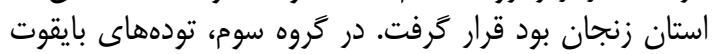

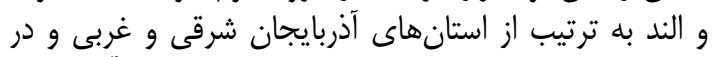

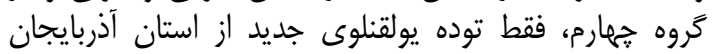

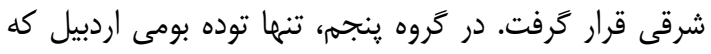

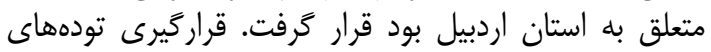

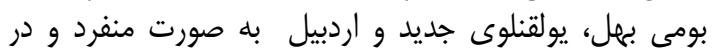

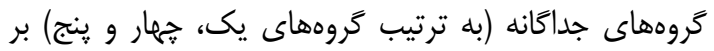

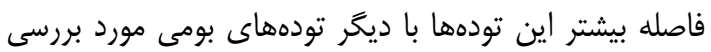

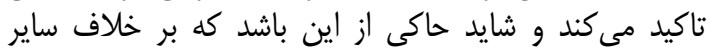

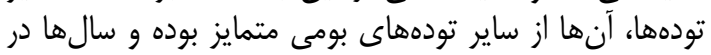

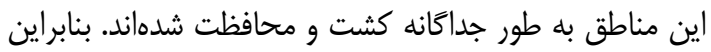

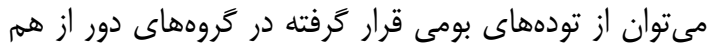


ريزماهوارهاى مورد استفاده در اين تحقيق، نشانكرهاى

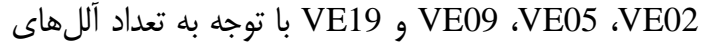

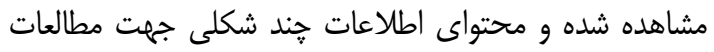

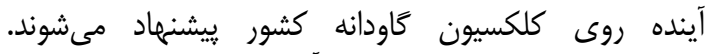

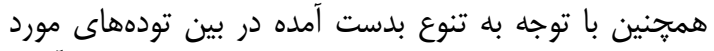

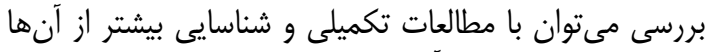
در برنامههاى اصلاحى آتى استفاده كرد.

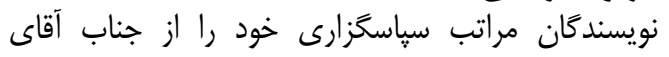

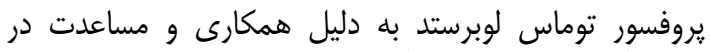

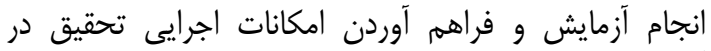

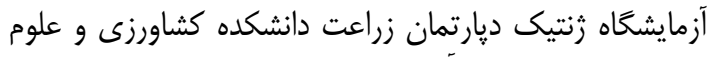
زيستى دانشخاه ايالتى آيوا، ايالات متحده امريكا ابراز مى دارنداندا
تبيين تغييرات مولكولى در تجزيههاى جناي متغيره مانند تجزيه

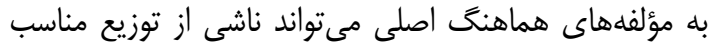

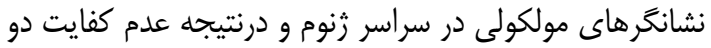

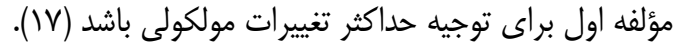

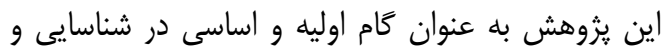

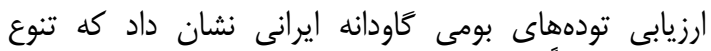

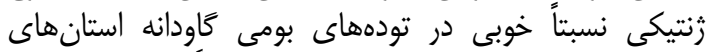
غرب كشور با وجود فاصله جغرافيايى نسبتاً كم بين توداني تودهانها

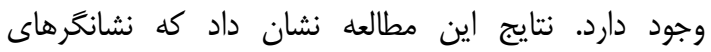

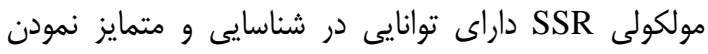

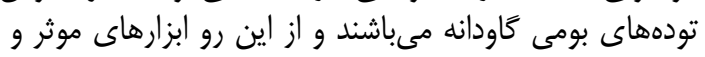

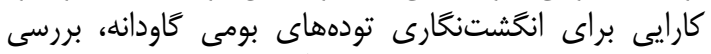

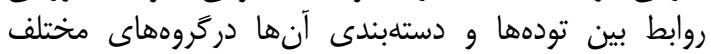

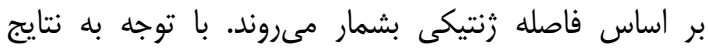
حاصل از تجزيه و تحليل دادههاى SSR، ازئي ميان نشانكر هاى

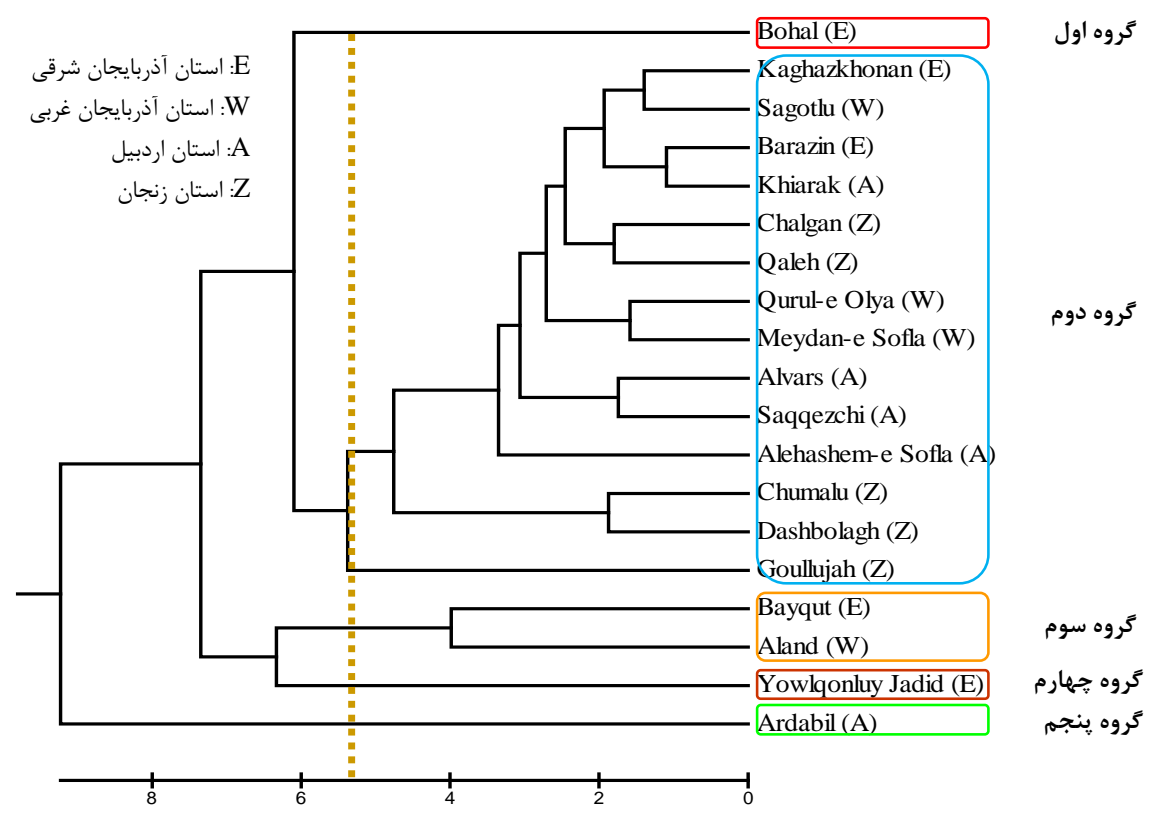

شكل r- گروهبندى تودههاى كَاودانه مورد مطالعه بر اساس دادهاى مولكولى نشانكر SSR به به روش UPGA Figure 2. Classification of bitter vetch landraces based on SSR markers using UPGMA method 


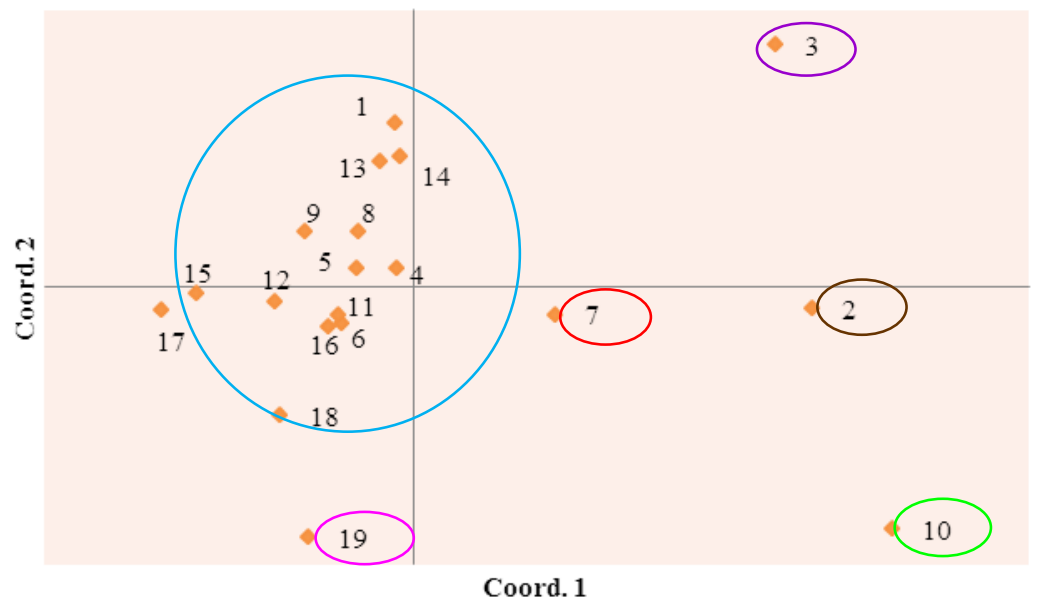

شكل ץ- يراكنش 19 توده بومى كَاودانه بر اساس دو مؤلفه اول حاصل از تجزيه به مؤلفههاى اصلى هماهنگ حاصل از دادههاى ريزماهواره Figure 3. Transmittance of 19 bitter vetch landraces on the first two axes derived from principle coordinate analysis using microsatellite data

1. Abbasi, M.R., S. Vaezi and N. Baghaie. 2007. Genetic diversity of bitter vetch (Vicia ervilia) collection of the National Plant Gene Bank of Iran based on agro-morphological traits. Iranian Journal of Rangelands and Forests Plant Breeding and Genetic Research, 15: 113-128 (In Persian).

2. Abdullah, A.Y., M.M. Muwalla, R.I. Qudsieh and H.H. Titi. 2010 .Effect of bitter vetch (Vicia ervilia) seeds as a replacement protein source of soybean meal on performance and carcass characteristics of finishing Awassi lambs. Tropical Animal Health and Production, 42: 293-300.

3. Amini, J., S. Razaghzadeh and A. Mohsenpour Azari. 2001. The effects of use of Lathyrus sativus instead of soybean meal in broiler chicken nutrition. The $3^{\text {rd }}$ Research Seminar of Poultry and Livestock Nutrition, 239-247 (In Persian).

4. Collard, B.C.Y., M.Z.Z. Jahufer, J. Brouwer and E.C.K. Bandpang. 2005. An introduction to markers, quantitative trait loci (QTL) mapping and marker-assisted selection for crop improvement: The basic concept. Euphytica, 142: 169-196.

5. Davis, P.H. and U. Plitwan. 1990. Vicia. In: Davis, P.H. (eds.) Flora of Turkey. Edinburgh University Press, Edinburgh Scotland, 3: 274-325.

6. Doyle, J.J. and J.L. Doyle. 1987. Rapid DNA isolation procedure for small quantities of fresh leaf tissue. Phytochemical Bulletin, 19: 11-15.

7. Ebrahimi, T., G.A. Ranjbar, G. Nematzadeh and G. Kiani. 2013. Molecular tagging of stem anthocyanin gene in rice using SSR markers. Journal of Crop Breeding, 5: 60-68 (In Persian).

8. ElFatehi, S., G. Béna, L. Sbabou, A. Filali-Maltouf and M. Ater. 2013. Preliminary results for use SSR markers in bitter vetch "Vicia ervilia (L.) willd. International Journal of Research in Agriculture and Food Science, 1: 40-46.

9. Farrokhi, J. and L. Naseri. 2012. Genetic diversity survey of Iranian native apples (Malus $\times$ domestica) genotypes using SSR markers. Agricultural Biotechnology, 10: 27-34 (In Persian).

10. Feg, F., M. Chen, D. Zhang, X. Sui and S. Ha. 2009. Application of SRAP in the genetic diversity of Pinus koraiensis of different provenances. African Journal of Biotechnology, 8: 1000-1008.

11. Fotovat, R. 1996. Estimation of the mating system of bitter vetch using Isozyme CPT and study of genetic diversity. M.Sc. Thesis, Tabriz University, 99 pp (In Persian).

12. Ganjkhanlo, A., S.A. Mohammadi, M. Moghadam, K. Ghasemi Golazani, M.R. Shakiba and A. Yosefi. 2012. Genetic diversity in barley as revealed by microsatellite markers and association analysis of these markers by traits related to freezing tolerance. Seed and Plant improvement Journal, 28: 101-114 (In Persian).

13. Haddad, S.G. 2006. Bitter vetch grains as a substitute for soybean meal for growing lambs-livestock. Science, 99: 221-225.

14. Hoshyardel, F., R. Darvishzadeh, A. Basirnia and H. Hatami Maleki. 2016. Association mapping of agronomic traits in oriental tobacco (Nicotiana tabacum L.) genotypes. Journal of Crop Breeding, 8: 134-143 (In Persian). 
15. Lopez Belido, L. 1994. Legumes for animal feed. http://www.hortprudue.edu./new crop/1492/legume-animal.html.

16. Matus, I.A. and P.M. Hayes. 2002. Genetic diversity in three groups of barley germplasm assessed by simple sequence repeats. Genome, 45: 1095-1106.

17. Mohammadi, S.A. and B.M. Prasanna. 2003. Analysis of genetic diversity in crop plants salient statistical tools and consideration. Crop Science, 43: 1235-1248.

18. Muminovic, J., A.E. Melchinger and T. Lubberstedt. 2004. Genetic diversity in cornsalad (Valerianella locusta) and related species as determined by AFLP markers. Plant Breeding, 123: 460-466.

19. Nei, M. 1972. Genetic distance between populations. The American Naturalist, 106: 283-292.

20. Razmazar, V., N.M. Torbatinejad, J. Seifdavati and S. Hassani. 2012. Evaluation of chemical characteristics, rumen fermentation and digestibility of Vicia sativa, Lathyrus sativus and Vicia ervilia grain by in vitro methods. Journal of Animal Science Researches, 22: 107-119 (In Persian).

21. Reif, J.C., X.C. Xia, A.E. Melchinger, M.L. Warburton, D.A. Hoisington, D. Beck, M. Bohn and M. Frisch. 2004. Genetic diversity determined within and among CIMMYT maize population of tropical, subtropical and temperate germplasm by SSR markers. Crop Science, 44: 326-334.

22. Rotger, A., A. Ferret, S. Calsamiglia and X. Manteca. 2006. In situ degradability if seven plant protein supplements in hifers fed high concentration diet with different forage to concentrate ratio. Animal Feed Science and Technology, 125: 73-87.

23. Sadeghi, G.H., J. Pourreza, A. Samei and H. Rahmani. 2009. Chemical composition and some antinutrient content of raw and processed bitter vetch (Vicia ervilia) seed for use as feeding stuff in poultry diet. Tropical Animal Health and Production, 41: 85-93.

24. Sahhafi, S.R. and B. Maleki Zanjani. 2016. Analysis of genetic variation for morphological and agronomic traits in bitter vetch landraces. The $2^{\text {nd }}$ international and $14^{\text {th }}$ National Iranian Crop Science Congress, 1-5 (In Persian).

25. Snowdon, R.J. and W. Fried. 2004. Molecular markers in Brassica oilseed breeding, current status and future possibilities. Plant Breeding, 123: 1-8. 


\title{
Evaluation of Genetic Diversity in Some Iranian Bitter Vetch Landraces using Microsatellite Markers
}

\section{Seyed Rasoul Sahhafi ${ }^{1}$, Bahram Maleki Zanjani ${ }^{2}$, Majid Talebi ${ }^{3}$ and Reza Fotovat ${ }^{4}$}

1- Assistant Professor, Vali-e-Asr University of Rafsanjan (Corresponding author: s.r.sahhafi@ vru.ac.ir)

2 and 4- Associate Professor and Assistant Professor, University of Zanjan

3- Associate Professor, Isfahan University of Technology

Received: October 18, $2015 \quad$ Accepted: January 24, 2016

\begin{abstract}
The genetic diversity of 19 bitter vetch landraces (Vicia ervilia L.) from four provinces (East Azerbaijan, West Azerbaijan, Ardabil and Zanjan) of Iran was evaluated using 18 pairs of SSR primers. The extracted genomic DNA was amplified with eight pair primers and PCR products were separated on DNA sequencing gels. In this research, eight pair of SSR primers detected a total of 27 alleles. Primers VE02, VE05, VE07, VE09 and VE19 with four alleles had the highest and VE14 and VE27 with two alleles had the lowest number of alleles among the SSR markers employed. The average of observed heterozygosity was 0.0435 . According to Chisquare test, populations were out of Hardy-Weinberg equilibrium. The results showed that the average of polymorphism information content (PIC) of primers was 0.5363. Primer VE02 had the highest PIC (0.6934) and primer VE27 had the lowest PIC (0.1093). The highest genetic distance was observed between Ardabil (from Ardabil province) with Chumalu (from Zanjan province) landraces. The least genetic distance was observed between Barazin (from East Azerbaijan province) and Khiarak (from Ardabil province) landraces. Cluster analysis based on Nei similarity coefficient matrix using UPGMA method classified the landraces into five main groups. The results indicated that SSR markers are efficient in case of polymorphism detection and genetic distance evaluation between Iranian bitter vetch landraces, and can be used as valuable tools in analysis of genetic relationships between bitter vetch landraces.
\end{abstract}

Keywords: Bitter vetch, Genetic diversity, Molecular markers, SSR 